\title{
Obstacles to Success of Students with Autism Spectrum Disorder in General Education Settings
}

\author{
Glennda K. McKeithan ${ }^{1}$, Douglas Cullinan², Malinda L. Pennington³ ${ }^{3}$ David S. Conroy ${ }^{4}$ \\ ${ }^{1}$ Department of Special Education, University of Kansas, Kansas, United States \\ ${ }^{2}$ College of Teacher Education and Learning Sciences, North Carolina State University, North Carolina, United States \\ ${ }^{3}$ College of Education, East Carolina University, North Carolina, United States \\ ${ }^{4}$ Eastern Wayne High School Mathematics Department, Wayne County Schools, North Carolina, United States \\ Correspondence: Glennda McKeithan, Department of Special Education, 1122 W. Campus Road, JRP, Lawrence, KS \\ 66045, United States.
}

Received: Aug. 9, $2020 \quad$ Accepted: Oct. 8, $2020 \quad$ Online Published: Oct. 11, 2020

doi:10.11114/jets.v8i11.5039 URL: https://doi.org/10.11114/jets.v8i11.5039

\begin{abstract}
The purpose of this study was to survey teacher opinions of 14 potential obstacles to teaching in general education classes attended by students with autism spectrum disorder (ASD). The anonymous participant responses were received from 16 elementary school teachers, 60 middle school teachers, and 131 high school teachers. Participants completed a questionnaire in which they rated 14 items. Rating data were uploaded to STATA data analysis software. The Kruskal-Wallis (K-W) statistic was used to analyze and interpret the data. Results identified items that significantly discriminated among teachers of the three grade levels and show a difference in the perceptions of teachers at different grade levels for some obstacles. Teachers at the elementary school level generally perceived greater obstacles than teachers at the middle school level, who perceived greater obstacles than those at the high school level. The results can be considered by educators and service providers when identifying professional development topics and resources to assist educators and service providers in the provision of instruction to maximize the potential for academic and social success for students with ASD in general education settings.
\end{abstract}

Keywords: autism spectrum disorder, general education, secondary students, obstacles to teaching, teacher perceptions

\section{Introduction}

Autism spectrum disorder (ASD) consists of complex neurodevelopmental disorders characterized by deficits in social and communication skills as well as unusual patterns of behavior (American Psychiatric Association, 2013). The exact prevalence of ASD varies significantly according to age, geographic location and identification criteria/procedure. The prevalence of ASD has increased significantly in the past twenty years. In 2019, the Centers for Disease Control and Prevention reported the prevalence of ASD to be about 1 in 54 children (1.8\%) (Christensen, et al., 2019). Kogan et al. (2018) reported the prevalence to be as high as 1 in $40(2.5 \%)$ children in the United States. There is also evidence to suggest that the prevalence of school aged children in the United States with ASD may be higher than previously reported. This may be due to cultural, ethnic and gender differences and the fact that many students with ASD who have the ability to meet academic expectations go undiagnosed (Travers, Krezmien, Mulcahy, \& Tincani, 2014). Regardless of the exact numbers, ASD is a rapidly growing developmental disorder among school aged children. Given that the majority of children with ASD have at least average intellectual ability, they are often served in general education settings. Unfortunately, many general educators have students with ASD who exhibit learning and behavior problems that they are unable to address satisfactorily (LePage \& Courey, 2014; Wittenburg, Cimera, \& Thoma, 2019).

Students with ASD in general education classes often experience difficulty with academic and social success in school because general education teachers may not be familiar with the characteristics and/or best practices associated with teaching students with ASD (Simpson \& McGinnis-Smith, 2019). In part this may be because scientific research is limited as to effective instructional and behavior management practices for students with ASD in general education (Riccomini, Morano, \& Hughes, 2017; Steinbrenner et al., 2020). Individuals with mild ASD are often served in less restrictive settings such as the general education classroom. Learners with ASD in regular classrooms may exhibit 
verbal and communication skills allowing them to participate (to some extent) in those educational settings. However, it is important for educators and service providers to remember that significant language and communication difficulties including expressive, receptive, and nonverbal skills are core deficits necessary for an ASD diagnosis (deBruin et al., 2013). Therefore, it is essential to remember that learners with ASD who are fluently verbal may still have communication and social skill needs that must be addressed (even if their needs are more subtle/less obvious). Educators and service providers must learn the observation and analysis skills needed to recognize and understand the subtle communication needs of these learners to maximize their potential through the learning process (Thomeer, McDonald, Rodgers, \& Lopata, 2019; Zajic et al., 2018).

Learning is a multifaceted process, and academic success depends on solid communication and social interaction skills in all settings (Wei, Yu, Shattuck, \& Blackorby, 2017). Communication literacy requires proficient reading, writing, listening, speaking and viewing skills. Effective learners use all these communication strands to acquire new understanding, knowledge, behaviors, skills, values, attitudes, and preferences. All learners must be able to articulate when and how their academic needs are not being met (McIntyre et al., 2017; McKeithan \& Sabornie, 2019). A student who can effectively ask questions and get help from a teacher will often be more successful than students who remain silent even when they are unsure of what is being asked of them. Learners with ASD often demonstrate uneven oral communication skills. For example, learners with ASD may have rich vocabularies and have no problem pronouncing words (Quill \& Stansberry-Brusnahan, 2017; Zajic et al., 2018). Additionally, learners on the spectrum may be able to engage in conversations with adults who guide the conversation, or they may be able to speak at length about topics of interest. However, many individuals with ASD have difficulty using language effectively, especially when they talk to unfamiliar people or about unfamiliar topics. Many students with ASD have problems with the meaning and rhythm of words and sentences. These students may be unable to understand body language and the nuances of vocal tones. Often, learners with ASD in less restrictive settings may be aware of their struggles engaging in two-way conversations and extended social communication (McKenney et al., 2016; Simpson \& McGinnis-Smith, 2019).

Learners with ASD may have difficulty responding to open ended questions (e.g., What should you do first?) because they may be overwhelmed by the number of possible responses. Uneven oral communication skills are tightly connected to student achievement and must be addressed in student service delivery plans. Developing age- and ability-appropriate speaking and listening skills are necessary for learners with ASD to engage in a variety of rich, structured conversations - as part of a whole class, in small groups, and with a partner (Simpson \& McGinnis-Smith, 2019; Thomeer, McDonald, Rodgers, \& Lopata, 2019). Being productive members of these conversations require learners to contribute accurate, relevant information. Effective communication skills often noted as challenges for learners on the spectrum include being able to respond to and develop what others have said, making comparisons and contrasts as well as analyzing and synthesizing ideas in various domains (Quill \& Stansberry-Brusnahan, 2017). Learners with ASD may have difficulty with initiating and participating effectively in discussions with diverse partners (one-on-one, groups, teachers) across topics, texts, and issues. Students with ASD may have difficulty building on others' ideas and expressing their own thoughts clearly. All core content areas requiring learners with ASD to read, write, listen, respond to, analyze, and interact with others and/or materials have the potential to be challenging for learners on the spectrum (Precise, Finch, \& Macgregor, 2018; Riccomini, Morano, \& Hughes, 2017).

The practical implication of the study findings would be to identify what teachers need to learn more about in order to help them more effectively address the needs of learners with ASD make satisfactory academic progress. For this to happen, it is necessary to obtain the perspectives of their general education teachers. Knowing what general education teachers believe are potential obstacles to student success would help focus professional development and training for teachers which could maximize opportunities for successful inclusion of students with ASD. The research purpose is to help educators and others involved in service delivery make better-informed decisions about instruction, behavior management, and other forms of support needed to help teachers maximize the potential for success of students with ASD in less restrictive settings (Precise, Finch, \& Macgregor, 2018; Stokes et al., 2017). Results could be used to make decisions about teacher training which can help educators and service providers to identify and utilize evidence based practices (EBPs) designed to assist learners with ASD (McIntyre et al., 2017). Such knowledge may also direct research toward reducing or removing those obstacles perceived as most important by the general education teachers who are expected to help such students achieve success in school.

\subsection{Research Purpose}

The purpose of the study was to survey teacher perceptions of 14 potential obstacles to teaching students with ASD. Each obstacle was presented as a questionnaire item. The word some was utilized to possibly avoid bias; researchers did not want participants to believe each problem listed should be perceived as expected obstacles to teaching. Each statement was followed by examples. Teachers read each item, considered the obstacle, and rated the extent that item described an obstacle to successful teaching of at least one student with ASD. The current literature does not offer a 
wealth of information relating to the needs of older students with ASD in general education settings, nor is sufficient information available about how to address those needs (McKenney et al., 2016; Steinbrenner et al., 2020). The research is focused on younger, lower functioning students. This study addresses the gap in the relevant research (published scholarship) by utilizing data generated from questionnaires completed by teachers in two public school systems related to the needs of students with ASD in elementary, middle and high school general education classes.

\subsection{Relevant Scholarship}

As previously stated, the literature suggests an increase in the number of students with ASD in general education (Amor et al., 2019). A literature search was conducted to identify research-based academic and behavioral interventions utilized to help students with ASD in general education. The target behaviors in each study were collected as suggestive of the challenges presented by students with ASD. The search used the terms (autis*, Asperger, or PDD) AND (math* OR English OR language* OR scien* OR social studies OR academic OR behavior OR social skills) AND (intervention OR strateg*) AND (school*) AND (general ed* OR regular ed* OR inclus*). This search included websites, books and scholarly, peer reviewed journals from 1983-2019. The research Databases searched were: Academic Search Complete, ERIC, Psych Info, PsycARTICLES, and PsycINFO.

The search of the literature included a review of 2,400+ single case design studies and meta-analyses as well as descriptive and systematic reviews of the literature (deBruin et al., 2013; Roberts \& Simpson, 2016; Stokes et al., 2017). Based on the target behaviors found in the literature review, the most common problems addressed in these studies included four areas of need which mirror those identified in the literature base 1) academic difficulties -written language, comprehension, spelling, questioning, higher order thinking and reasoning; 2) social interactions -with peers and adults, behavior problems, communication -expressive and receptive language; 3) organization difficulties; and 4) self-advocacy (Amor et al., 2019; Steinbrenner et al., 2020; Zajic et al., 2018). Caution should be observed when interpreting these target behavior-based problems as they are indirect indicators of the challenges of students with ASD selected to participate in single-case-design intervention studies based on individual needs. Other significant problems of students with ASD may not have been chosen as target behaviors in these studies or attempts to improve them may have been unsuccessful and not published. To accurately assess student needs, it is necessary to obtain data directly from teachers familiar with academic and social challenges in their classrooms. The teacher questionnaire instrument used in this study was developed to generate data needed to identify and further analyze such challenges.

\section{Method}

\subsection{Participants}

The participants were 207 general education teachers in public elementary, middle, and high schools in two school districts in North Carolina. District A was a large school district covering urban and suburban areas, while District B was a small city school district. In both school districts, a contact person communicated a request to teachers (via email) to participate if at least one student with ASD was enrolled in their class(es). Participation consisted of responding to a ASD Questionnaire (ASDQ), developed for the present study based on the needs identified in the literature review. Sixteen elementary teachers, 60 middle school teachers, and 131 high school teachers responded.

\subsection{Materials}

Data on obstacles were collected via participant completion of the ASDQ. The ASDQ consists of 14 rated items addressing possible obstacles to successful teaching that might be created by learning and behavior problems that students with ASD sometimes exhibit. In addition to reviewing the literature, experts in autism (university level researchers and autism professionals in the field of education with at least graduate degrees) were asked to review the survey and provide feedback related to whether the survey items were in line with potential obstacles to student success in general education settings. The 14 rated items were determined in consideration of a review of literature on ASD. A paper copy of the qualtrics survey can be viewed using the link below. The open-ended responses were not considered in this study. http://bit.ly/HFAObstaclesSurvey

\subsection{Procedures}

We obtained permission to engage in research from the school districts and the university. We assured anonymity for participating teachers, schools, students, and districts by converting the ASDQ into an online format via a website that did not collect information about respondents except school level (elementary, middle, high school). The need for participant anonymity introduced a research limitation discussed later. Participants rated the extent to which items described an obstacle to teaching, not particular students: $0=$ not an obstacle, $1=$ small obstacle, $2=$ considerable obstacle and $3=$ very large obstacle. 


\subsection{Analysis}

Rating data were uploaded to STATA (Version IC 13.1) data analysis software. The analysis was conducted in steps. In the first, the three grade-level groups (elementary, middle, high school) were compared, separately for each item. In step two, items for which a null hypothesis of no differences involving the three groups was rejected received further analysis to determine which pairs of teacher groups (e.g., elementary vs middle) differed significantly.

\subsubsection{Step One}

The null hypothesis of no difference involving the three groups was tested using the Kruskal-Wallis (K-W) statistic (Chan \& Walmsley, 1997). This test is appropriate because the data are ordinal and originated from multiple independent groups. A significant K-W test statistic for any particular item would mean that for that item, there must be at least one difference involving the three groups (e.g., middle vs high school).

To prevent inflation of alpha, we considered the 14 three-group comparisons as a family of comparisons. Thus the .05 alpha level was applied to the family instead of separately to each of the 14 comparisons, which potentially would inflate alpha (Sirkin, 2006). This was accomplished as follows: We arranged the K-W test results for items in order of largest to smallest, along with each test result's $p$ value ( $p$ values arranged smallest to largest). Next, we added the $p$ values beginning with the smallest $p$ value and continuing until the cumulative sum of $p$ values approached but did not exceed .05. Items whose $p$ values met this standard were deemed statistically significant. Only those items qualified for further examination in step two.

\subsubsection{Step Two}

An item that was significant in step one was further analyzed to identify which pairwise comparison(s) among the three groups produced the significant K-W statistic. This analysis was performed using the Wilcoxon Mann-Whitney (WM-W) statistic (Corder \& Foreman, 2009), which is essentially a two-group version of the K-W. A significant WM-W test statistic for any comparison of two groups would mean that those groups rated that item differently.

As with step one analyses, we addressed the possibility of alpha inflation in the step two analyses (assuming some items qualify for step two). For the collection of items that qualified for step two analysis, we designated three families of pairwise comparisons: elementary vs middle, elementary vs high, and middle vs high. The .05 alpha level was applied separately to each family as follows: for step two items we arranged WM-W test results largest to smallest, along with each test result's $p$ value. Thus $p$ values were arranged smallest to largest. Next, we added the $p$ values, beginning with smallest $p$-value and continuing until the cumulative sum of $p$ values approached but not exceed .05. Pairwise comparisons whose $p$ values met this standard were deemed statistically significant.

\section{Results}

\subsection{Step One Results: Three-Group Comparisons by Item}

Table 1 presents K-W chi2 results that compare ratings of items by elementary, middle, and high school teachers. There was a statistically significant difference for: 1. academic engagement, 7. survival skills, 4. written expression, 10. upset by sensations, 5. oral expression, 2. learning difficulties, and 3. social problems at school. That is, applying the family-wise rule for alpha $\leq .05$, the accumulation of $p$-values for these seven items approached but did not exceed .05 . These items therefore qualified for stage two analysis. For each item, statistical significance means that among the three groups, there is at least one more particular comparison that is statistically significant. However, the overall $\mathrm{K}-\mathrm{W}$ results cannot identify such more particular comparisons, so they are followed up with pairwise comparisons. 
Table 1. Kruskal-Wallis chi-square results comparing distributions of teaching obstacles reported by general educators of students with ASD in public school classrooms

\begin{tabular}{clccc}
\hline Item1 & \multicolumn{1}{c}{ Item Name } & Chi2 Value & $p$ value & Cumulative $p$ value \\
\hline 1 & Academic engagement & 18.76 & .000 & $.000^{*}$ \\
7 & Survival skills & 16.84 & .000 & $.000^{*}$ \\
4 & Written expression & 14.71 & .001 & $.001^{*}$ \\
10 & Upset by sensations & 13.42 & .001 & $.002^{*}$ \\
5 & Oral expression & 11.74 & .003 & $.005^{*}$ \\
2 & Learning difficulties & 10.84 & .004 & $.009^{*}$ \\
3 & Social problems school & 7.80 & .020 & $.029^{*}$ \\
9 & Disorganization & 6.57 & .037 & .066 \\
6 & Receptive language & 5.68 & .058 & .124 \\
8 & Depend structure & 5.30 & .071 & .195 \\
12 & Emotional reactions & 4.93 & .085 & .280 \\
13 & Peer mistreatment & 1.34 & .512 & .792 \\
14 & Social problems other & 1.00 & .607 & 1.399 \\
11 & Distracting behavior & .96 & .620 & 2.019 \\
\hline
\end{tabular}

Note. Items are presented in order of increasing $\mathrm{p}$ value; Chi-square values calculated in consideration of ties

* Item is significant at $p=.05$, according to the stated family wise procedure

\subsection{Stage Two: Pairwise Comparisons Between Grade Level Groups}

\subsubsection{Elementary vs Middle School General Educators}

Table 2. Wilcoxon Mann-Whitney rank sums, expected sums, z scores and probability for teaching obstacle ratings by general educators of students with ASD in public school classrooms.

\begin{tabular}{|c|c|c|c|c|c|c|c|c|c|}
\hline Item & $\begin{array}{l}\text { Elem } \\
\text { Rank } \\
\text { Sum } \\
\end{array}$ & $\begin{array}{c}\text { Elem } \\
\text { Expected } \\
\text { Rank Sum } \\
\end{array}$ & $\begin{array}{c}\text { Middle } \\
\text { Rank Sum }\end{array}$ & $\begin{array}{c}\text { Middle } \\
\text { Expected } \\
\text { Rank Sum } \\
\end{array}$ & $\begin{array}{l}\text { Combined } \\
\text { Rank Sum }\end{array}$ & $\begin{array}{c}\text { Combined } \\
\text { Expected Rank } \\
\text { Sum } \\
\end{array}$ & $\begin{array}{c}z \\
\text { score }\end{array}$ & $p(|z|>0)$ & $\begin{array}{c}\text { Cumulative } \\
p\end{array}$ \\
\hline 5. Oral & 775.5 & 616 & 2150.5 & 2310 & 2926 & 2926 & 2.19 & 0.029 & $0.029^{*}$ \\
\hline \multicolumn{10}{|l|}{ Expression } \\
\hline 4. Written & 777 & 616 & 2149 & 2310 & 2926 & 2926 & 2.15 & 0.032 & 0.061 \\
\hline \multicolumn{10}{|l|}{ Expression } \\
\hline 1. Academic & 735 & 616 & 2191 & 2310 & 2926 & 2926 & 1.61 & 0.107 & 0.229 \\
\hline \multicolumn{10}{|l|}{ Engagement } \\
\hline $\begin{array}{l}\text { 2. Learning } \\
\text { Difficulties }\end{array}$ & 703.5 & 616 & 2223 & 2310 & 2926 & 2926 & 1.18 & 0.239 & 0.641 \\
\hline $\begin{array}{l}\text { 10. Upset by } \\
\text { (Sensations) }\end{array}$ & 699 & 616 & 2227 & 2310 & 2926 & 2926 & 1.14 & 0.255 & 0.896 \\
\hline 3. Social & 655 & 616 & 2271 & 2310 & 2926 & 2926 & 0.53 & 0.597 & 1.493 \\
\hline \multicolumn{10}{|l|}{ Problems Sch } \\
\hline $\begin{array}{ll}7 . & \text { Survival } \\
\text { Skills } & \end{array}$ & 625 & 616 & 2301 & 2310 & 2926 & 2926 & 0.12 & 0.904 & 2.397 \\
\hline
\end{tabular}

Note. Items are presented in order of decreasing $z$ scores and increasing $p$ values

* Item is significant at $p \leq .05$, according to the stated familywise procedure

Table 2 presents WM-W rank sums, expected sums, $z$ scores, and associated probabilities for teaching obstacle questionnaire items that were significant in stage one. Table 2 covers only comparisons between elementary and middle school general educators of students with ASD. Adding the $p$ values until the cumulative sum approached but did not exceed .05 indicates that only item 5 , oral expression, was statistically significant. 


\subsubsection{Elementary vs High School General Educators}

Table 3. Wilcoxon Mann-Whitney rank sums, expected sums, $z$ scores and probability for teaching obstacle ratings by elementary and high school general educators of students with ASD in public school classrooms.

\begin{tabular}{|c|c|c|c|c|c|c|c|c|c|}
\hline Item \# & $\begin{array}{l}\text { Elem } \\
\text { Rank } \\
\text { Sum } \\
\end{array}$ & $\begin{array}{c}\text { Elem } \\
\text { Expected } \\
\text { Rank Sum } \\
\end{array}$ & $\begin{array}{c}\text { High } \\
\text { School } \\
\text { Rank Sum } \\
\end{array}$ & $\begin{array}{l}\text { High School } \\
\text { Expected } \\
\text { Rank Sum } \\
\end{array}$ & $\begin{array}{c}\text { Combined } \\
\text { Rank } \\
\text { Sum } \\
\end{array}$ & $\begin{array}{l}\text { Combined } \\
\text { Expected } \\
\text { Rank Sum } \\
\end{array}$ & $\begin{array}{c}z \\
\text { score }\end{array}$ & $\mathrm{p}(|z|>0)$ & $\begin{array}{c}\text { Cumulative } \\
p\end{array}$ \\
\hline $\begin{array}{l}\text { 4. Written } \\
\text { Expression }\end{array}$ & 1719 & 1184 & 9160 & 9694 & 10878 & 10878 & 3.54 & 0.000 & $0.000 *$ \\
\hline $\begin{array}{l}\text { 1. Academic } \\
\text { Engagement }\end{array}$ & 1696 & 1184 & 9183 & 9694 & 10878 & 10878 & 3.41 & 0.001 & $0.001 *$ \\
\hline $\begin{array}{l}5 . \quad \text { Oral } \\
\text { Expression }\end{array}$ & 1665 & 1176 & 9066 & 9555 & 10731 & 10731 & 3.29 & 0.001 & $0.002 *$ \\
\hline $\begin{array}{l}\text { 10. Upset by } \\
\text { (Sensations) }\end{array}$ & 1665 & 1176 & 9066 & 9555 & 10731 & 10731 & 2.71 & 0.001 & $0.003 *$ \\
\hline $\begin{array}{l}\text { 2. Learning } \\
\text { Difficulties }\end{array}$ & 1545 & 1184 & 9333 & 9694 & 10878 & 10878 & 2.37 & 0.018 & $0.038^{*}$ \\
\hline $\begin{array}{l}\text { 7. Survival } \\
\text { Skills }\end{array}$ & 1519 & 1168 & 9067 & 9417 & 10585 & 10585 & 2.35 & 0.019 & 0.057 \\
\hline $\begin{array}{lr}3 . & \text { Social } \\
\text { Prob } & \text { in } \\
\text { School } & \\
\end{array}$ & 1468 & 1184 & 9411 & 9694 & 10878 & 10878 & 1.86 & 0.062 & 0.119 \\
\hline
\end{tabular}

Note. Items are presented in order of decreasing $\mathrm{z}$ scores and increasing $\mathrm{p}$ values

* Item is significant at $\mathrm{p} p \leq .05$, according to the stated familywise procedure

Table 3 presents WM-W rank sums, expected sums, $z$ scores and probabilities for qualifying items, by elementary and high school grade level groups. Accumulating $p$ values to approach but not exceed .05 indicates that items 4 . written expression, 1. academic engagement, 5. oral expression, 10. upset by sensations, and 2. learning difficulties were statistically significant.

\subsubsection{Middle vs High School General Educators}

Table 4. Wilcoxon Mann-Whitney rank sums, expected sums, $z$ scores and probability for teaching obstacle ratings by middle and high school general educators of students with ASD in public school classrooms.

\begin{tabular}{|c|c|c|c|c|c|c|c|c|c|}
\hline Item \# & $\begin{array}{c}\text { Middle } \\
\text { Rank } \\
\text { Sum }\end{array}$ & $\begin{array}{l}\text { Middle } \\
\text { Expected } \\
\text { Rank } \\
\text { Sum }\end{array}$ & $\begin{array}{c}\text { High } \\
\text { School } \\
\text { Rank } \\
\text { Sum } \\
\end{array}$ & $\begin{array}{c}\text { High } \\
\text { School } \\
\text { Expected } \\
\text { Rank Sum }\end{array}$ & $\begin{array}{c}\text { Combined } \\
\text { Rank } \\
\text { Sum }\end{array}$ & $\begin{array}{l}\text { Combined } \\
\text { Expected } \\
\text { Rank Sum }\end{array}$ & $\begin{array}{c}z \\
\text { score }\end{array}$ & $p(|z|>0)$ & $\begin{array}{c}\text { Cumulative } \\
p\end{array}$ \\
\hline $\begin{array}{ll}7 . & \text { Survival } \\
\text { Skills } & \end{array}$ & 6947 & 5700 & 11009 & 12225 & 17955 & 17955 & 3.76 & 0.000 & $0.000 *$ \\
\hline $\begin{array}{l}\text { 1. Academic } \\
\text { Engagement }\end{array}$ & 6830 & 5760 & 11506 & 12576 & 18336 & 18336 & 3.24 & 0.001 & $0.001 *$ \\
\hline $\begin{array}{l}\text { 10. Upset by } \\
\text { (Sensations) }\end{array}$ & 6681 & 5730 & 11465 & 12415 & 18145 & 18145 & 2.90 & 0.004 & $0.005^{*}$ \\
\hline $\begin{array}{l}\text { 2. Learning } \\
\text { Difficulties }\end{array}$ & 6647 & 5760 & 11689 & 12576 & 18336 & 18336 & 2.64 & 0.008 & $0.013^{*}$ \\
\hline $\begin{array}{l}\text { 3. Social Prob } \\
\text { in School }\end{array}$ & 6568 & 5760 & 11779 & 12576 & 18336 & 18336 & 2.38 & 0.017 & $0.030^{*}$ \\
\hline $\begin{array}{l}4 . \quad \text { Written } \\
\text { Expression }\end{array}$ & 6470 & 5760 & 11866 & 12576 & 18336 & 18336 & 2.13 & 0.033 & 0.063 \\
\hline $\begin{array}{l}5 . \quad \text { Oral } \\
\text { Expression }\end{array}$ & 6246 & 5730 & 11899 & 12415 & 18145 & 18145 & 1.58 & 0.115 & 0.178 \\
\hline
\end{tabular}

Note. Items are presented in order of decreasing $\mathrm{z}$ scores and increasing $\mathrm{p}$ values

* Item is significant at $p=.05$, according to the stated familywise procedure

Table 4 presents WM-W rank sums, expected sums, $z$ scores and probabilities for qualifying items, by middle and high school grade level groups. Accumulating the $p$ values to approach but not exceed .05 indicates that items 7 . survival skills, 1. academic engagement, 10. upset by sensations, 2. learning difficulties, and 3. social problems in school were statistically significant.

\section{Discussion}

The authors distributed an electronic questionnaire to general education teachers of students with ASD. These teachers rated the extent to which each item described an obstacle to their teaching success. Ratings of elementary, middle, and high school teachers were grouped and compared statistically. Results indicated statistically significant differences by 
grade level as to what constituted the teacher's perceptions of obstacles to successful teaching. For all items on which there was a significant difference, teachers at the earlier grade level rated the item as a greater obstacle to their teaching success.

\subsection{Study Limitations}

Although the data clarify teacher judgments of obstacles associated with students who have different grade levels, the results must be interpreted with caution due to several method limitations associated with this study. First, the validity of this new questionnaire instrument, particularly its ability to accurately measure the desired constructs, was not examined empirically. Second, the reliability of each item on the questionnaire (ability to yield consistent results over time) was not studied. Additionally, coverage error, or the possibility that the questionnaire respondents may not sufficiently represent the target population of all general education teachers, is a limitation on interpretation of study results (Groves et al., 2011). For example, an obvious limitation is the small number of respondents, especially the total of only 16 teachers at the elementary level. The geographic generality of results is unknown because of the limited geographic representation of participants (two school districts in North Carolina). Teacher perceptions in these two districts which are relatively close to one another may not necessarily be representative of the perceptions of general education teachers of students within other geographic areas. The Institutional Review Board expressed concern that the protection of human subjects would be compromised unless the questionnaire was anonymous. Therefore, the researchers do not know how many teachers were invited to participate; this makes it impossible to calculate response rate.

\subsection{Research Needed}

Further investigation must explore reliability and validity of results by replicating the study. The distribution method of subsequent studies must solicit information from approximately the same number of teachers in all grade levels. This would likely increase the number of elementary and middle school teachers. A different participant selection process would be required to assure that the target population (general education teachers of students with ASD) was well represented in the study sample. Additional studies to advance the issue of helping students with ASD experience success would include a review of research studies of instructional practices to address identified obstacles to successful teaching in each grade level. Similarly, a review of research studies of social skill strategies to address identified obstacles would help key stakeholders by sharing effective interventions, which may vary by grade level.

\subsection{Implications for Practice}

Results of the questionnaire might be used by educators and service providers to obtain insight into obstacles often associated with less restrictive settings. Results may offer researchers and other stakeholders involved an opportunity to connect intervention strategies with specific needs. To help suggest such implications, the author conducted a third stage of analysis. The author focused on item ratings of either 2 or 3, the two highest ratings. This information, together with the author's logic and considerable teaching experience, suggested insights about obstacles and potential interventions at different levels. This third stage of analysis does not use statistical testing but does suggest possibilities that could lead to scientific evaluation.

Table 5. Frequency percentages of obstacle ratings $(0,1,2,3)$ by general educators of students with ASD in public school classrooms across settings

\begin{tabular}{|c|c|c|c|c|c|c|c|c|c|c|c|c|c|}
\hline \multirow[b]{2}{*}{ Item } & \multirow[b]{2}{*}{ Item Name } & \multicolumn{4}{|c|}{$\begin{array}{c}\text { Elementary School } \\
\text { Ratings } \\
\end{array}$} & \multicolumn{4}{|c|}{$\begin{array}{l}\text { Middle School } \\
\text { Ratings }\end{array}$} & \multicolumn{4}{|c|}{$\begin{array}{l}\text { High School } \\
\text { Ratings }\end{array}$} \\
\hline & & $\underline{\mathbf{0}}$ & $\underline{1}$ & $\underline{2}$ & $\underline{\mathbf{3}}$ & $\underline{\mathbf{0}}$ & 1 & $\underline{2}$ & $\underline{\mathbf{3}}$ & $\underline{\mathbf{0}}$ & 1 & 2 & $\underline{3}$ \\
\hline$\overline{1}$ & $\overline{\text { Acad Engag }}$ & $\overline{61}$ & $\overline{19}$ & $\overline{44}$ & $\overline{31}$ & $\overline{7}$ & $\overline{38}$ & $\overline{40}$ & $\overline{15}$ & $\overline{18}$ & $\overline{48}$ & $\overline{31}$ & $\overline{4}$ \\
\hline 2 & Learn Diff & 13 & 31 & 19 & 38 & 13 & 33 & 45 & 8 & 25 & 43 & 31 & 8 \\
\hline 3 & Soc Prob Sch & 6 & 19 & 44 & 31 & 3 & 28 & 43 & 25 & 9 & 40 & 35 & 16 \\
\hline 4 & Writ Express & 13 & 6 & 44 & 38 & 15 & 33 & 37 & 15 & 18 & 47 & 32 & 4 \\
\hline 5 & Oral Express & 0 & 25 & 69 & 6 & 12 & 50 & 27 & 12 & 21 & 47 & 29 & 4 \\
\hline 6 & Rec Lang & 6 & 38 & 19 & 38 & 20 & 37 & 33 & 10 & 17 & 51 & 22 & 10 \\
\hline 7 & Sch Surv & 19 & 25 & 50 & 6 & 15 & 40 & 30 & 15 & 36 & 41 & 18 & 5 \\
\hline 8 & Dep Struct & 6 & 31 & 56 & 6 & 22 & 42 & 26 & 7 & 22 & 47 & 25 & 6 \\
\hline 9 & Disorg & 0 & 38 & 44 & 19 & 15 & 40 & 28 & 17 & 21 & 40 & 33 & 6 \\
\hline 10 & Upset Sens & 13 & 31 & 38 & 19 & 12 & 53 & 22 & 13 & 31 & 45 & 21 & 3 \\
\hline 11 & Distrat Beh & 33 & 20 & 47 & 0 & 24 & 51 & 22 & 3 & 24 & 56 & 18 & 2 \\
\hline 12 & Emot React & 6 & 31 & 44 & 19 & 9 & 46 & 37 & 9 & 18 & 44 & 29 & 9 \\
\hline 13 & Peer Mistr & 47 & 47 & 7 & 0 & 38 & 39 & 19 & 3 & 44 & 41 & 12 & 3 \\
\hline 14 & $\begin{array}{l}\text { Soc } \quad \text { Prob } \\
\text { Other }\end{array}$ & 20 & 40 & 40 & 6 & 10 & 51 & 36 & 3 & 21 & 46 & 24 & 10 \\
\hline
\end{tabular}

Note. Percentage signs omitted. 
Table 5 presents, for each of the three grade levels, the percentage of respondents endorsing an item as Considerable Obstacle or Very Large Obstacle (rated either 2 or 3). On the sole item on which elementary and middle school teachers differed significantly, 5. oral expression. Table 5 shows that $75 \%$ of elementary school teachers but only $39 \%$ of middle school teachers rated this item 2 or 3 . This indicates that the elementary vs middle difference was not just statistically significant, but also fairly large. On the items on which elementary and high school teachers differed significantly, the percentages of respondents rating either 2 or 3 were as follows: item 5. oral expression, elementary, $75 \%$ versus high school, 33\%; item 1. academic engagement: elementary, 75\%, versus high school, 35\%; item 4. written expression: elementary, $82 \%$, versus high school, $36 \%$; item 9. disorganization: elementary, $63 \%$, versus high school, $39 \%$; and item 10. upset by sensations: elementary, $57 \%$, versus high school, $24 \%$. Table 5 shows that elementary teachers rated each of these items as a greater obstacle than did high school teachers.

Finally, on the items on which middle and high school teachers differed significantly, the percentages of respondents rating either 2 or 3 were as follows: item 2. learning difficulties: middle school, $53 \%$, versus high school, 39\%; item 1 . academic engagement: middle school, 55\%, versus high school, 35\%; item 10. upset by sensations: middle school, 35\%, versus high school, 24\%; item 5. oral expression: middle school, 39\%, versus high school, 33\%; and item 3. social problems in school: middle school, 68\%, versus high school, 51\%. Table 5 shows that middle school teachers rated these items as a greater obstacle than did high school teachers.

Table 5 helps make it clear that higher item ratings ( 2 or 3 ) were more characteristic of elementary than middle school teachers, and of middle than high school teachers. Elementary item percentages ranged from $7 \%-82 \%$; middle school percentages ranged from $22 \%-68 \%$, and high school percentages ranged $15 \%-51 \%$. Elementary level interpretations. Judging by percentages of teachers rating 2 or 3 (regardless of statistical significance), the items likely to be obstacles for elementary were written expression (82\%), social problems in school $(75 \%)$, academic engagement (75\%), disorganization (63\%), and upset by sensations $(57 \%)$. These ratings may be related to the fact that the early school years are the beginning of formal literacy development. Written expression is a high priority in elementary because this skill is linked to all subject areas.

During the elementary years, areas of communication literacy addressed in this study (written expression, oral expression) are developed simultaneously. Typically, in elementary school settings, classes are smaller. The lower student-teacher ratios can make it more likely that there are more adults available to spend greater amounts of time with individual learners to identify areas of need and help their students to develop these skills. Academic engagement with adults and peers is crucial for learners on the spectrum during this period of development (McKeithan \& Sabornie, 2019; Quill \& Stansberry-Brusnahan, 2017). Many elementary level classes are linked to structured expectations, and compliance with school rules and organization are integrated into the curriculum throughout the school day. Social skills are integrated into organized and structured routines as adults teach learners to develop and enhance social interaction as well as academic skills needed to progress through their school careers. Students with deficits in these areas would be more easily noted than they may be in middle or high school settings because high school teachers may be less aware of specific student needs that are not easily observed in a large classroom for a short period of time (Abate, 2018; Simpson \& McGinnis-Smith, 2019; Walker et al., 2017).

Learners with ASD often struggle with adjusting to the social and academic demands of middle school settings (McKeithan \& Sabornie, 2019). Judging by Table 5 percentages of teacher's rating 2 or 3 (regardless of statistical significance), the items most likely to be obstacles for middle school teachers were: social problems in school (68\%), academic engagement (55\%), learning difficulties (53\%), and written expression (52\%). Teacher ratings at this level may be associated with higher teacher expectations in regard to student maturity as well as an increased demand for mastery of academic content. Class sizes are larger, students change classes, and they spend less time with the same peers or teachers. Students with ASD may find it more difficult to effectively communicate with and socialize (deBruin et al., 2013). In the middle school settings, there is a greater focus on standardized tests and meeting grade level standards and academic milestones. As a result, learners with ASD served in general education settings often experience decreased time in special education. The class sizes are larger, and teachers are often at a loss for how to implement EBPs to help all learners remain on pace to meet expected milestones (McKeithan \& Sabornie, 2020; Precise, Finch, \& Mcgregor, 2018). These factors may account for a shift of teacher concerns from elementary to middle school level. The middle school environment is different from elementary (fewer structured routines, less direct support from teachers). Students are increasingly responsible for working cooperatively with peers and demonstrating the ability to use writing to communicate (Quill \& Stansberry-Brusnahan, 2017). Standardized assessments require student writing assignments to be structured, organized, appropriately developed and evidence based. Given that students with ASD have deficits in this area, these skills are likely a challenge. Judging by Table 5 percentages of teachers rating 2 or 3 (regardless of statistical significance), the items most likely to be obstacles for high school teachers were: social problems in school (51\%), disorganization (39\%), written expression (36\%), and academic engagement (35\%). High school students 
experience increased academic and social interaction demands.

The social development levels of adolescents might be a contributing factor to the increase in social deficits in this setting. It is interesting that high school teachers ranked social problems as a significant need, but mistreatment by peers was not a concern. These findings may be due to the fact that many high school teachers expect students to have already developed the social and communication skills needed for successful interactions in the high school setting. Many general education classes at the high school settings have very large class sizes. Often, educators at this level interact more with entire classes than they do with individual students. Learners with ASD who have difficulty asking for help and actively engaging in collaborative groups may find this format challenging (Quill \& Stansberry-Brusnahan, 2017). Adolescents are more observant and sensitive to differences among their peers, and they may not be comfortable helping peers with less obvious communication and social skill deficits. In addition, the focus of many high school classes is often on clearly defined academic objectives rather than the communication and social interaction skills (or functional academic needs) required to complete the tasks (McIntyre et al., 2017). However, these functional academic skills are vital for students to develop and manage in order to develop the skills needed to work cooperatively with others and prepare to transition into adulthood (Wittenburg, Cimera \& Thoma, 2019).

High school students must have sufficient independence and self-reliance to successfully interact with others in order to consistently demonstrate mastery of content (Wittenburg, Cimera \& Thoma, 2019). These skill deficits contribute to the increased need for students to develop effective executive functioning skills (i.e., organization, time-management, etc.) and be less dependent on teacher structure/assistance (McKenney et al., 2016). Students must have appropriate organization and written expression skills to demonstrate academic engagement, understand expectations and master concepts (Quill \& Stansberry-Brusnahan, 2017). This challenge, coupled with continued disorganization can become a major obstacle for learners with ASD.

The results of this study could be utilized when designing a holistic plan to better prepare teachers to help students transition into general education (Precise, Finch, \& Macgregor, 2018). For example, if disorganization and written language concerns are a major obstacle in high school, educators and service providers at the elementary and middle school levels might engage in professional development to learn to help students with executive functioning skills in order to prepare students for this challenge by integrating these skills into their instructional routine (Walker et al., 2017). Teachers must be trained to identify and apply EBPs to help students with ASD understand how what they are learning is relevant to motivate them to stay on task. Instructional presentation that is clear, assessment methods that are explicit, and teachers who utilize a routine can more effectively address the needs of all students. Teachers must be trained to identify and utilize effective instructional presentation methods naturally used by teachers of younger students, such as repetition and posted reminders of due dates and evaluation methods (Abate, 2018).

The practical implications of these results are that teachers of students with ASD may need to learn how to identify and effectively address challenges of students with ASD at different developmental levels and across subject content areas (McKenney et al., 2016; Wei, Yu, Shattuck, \& Blackorby, 2017). Gaining a solid understanding of student needs would help teachers determine if environmental variables and/or effective interventions at different levels could be implemented to help students as they progress through school. Experienced and preservice teachers must learn to connect research with practice by identifying EBPs proven to be effective for learners with ASD (Abate, 2018; Walker et al., 2017). Using strategies to teach and reinforce organization, problem solving, and functional interaction can potentially help students with ASD better understand how to manage the expected and unexpected problems in less restrictive settings. Examples of these are: seeking assistance, adjusting to schedule changes, losing or misplacing materials, and time management (McIntyre et al., 2017; Stokes et al., 2017). Since social skills deficits were ranked in the top five concerns across settings, a need is indicated to develop and utilize research-based instructional programs to effectively instruct educators and service providers to teach and to reinforce appropriate social interaction into their practice. If these results represent challenges of students with ASD in general education, then teachers must learn to include social skills instruction into their practice especially in relation to flexible grouping, reciting or presenting to the class, engaging in classroom dialogue without veering off topic or monopolizing, interacting with peers, having fun, sharing, or socializing outside of class, making and retaining friends or peer allies (Simpson \& McGinnis-Smith, 2019; Steinbrenner et al., 2020). Effective preparation and professional development of teachers will maximize the potential for academic and social success for students with ASD in general education settings.

\section{References}

Abate, D. J. (2018). Classroom for debate: When students with autism succeed in inclusive classrooms. Elements, 13(2). https://doi.org/10.6017/eurj.v13i2.10050

American Psychiatric Association. (2013). Diagnostic and statistical manual of mental disorders (5th ed.). Arlington, VA: American Psychiatric Association. https://doi.org/10.1176/appi.books.9780890425596 
Amor, A. M., Hagiwara, M., Shogren, K. A., Thompson, J. R., Verdugo, M. Á., Burke, K. M., \& Aguayo, V. (2019). International perspectives and trends in research on inclusive education: A systematic review. International Journal of Inclusive Education, 23(12), 277-1295. https://doi.org/10.1080/13603116.2018.1445304

Chan, Y., \& Walmsley, R. P. (1997). Learning and understanding the Kruskal-Wallis one-way analysis-of-variance-by-ranks test for differences among three or more independent groups. Physical therapy, 77(12), 1755-1761. https://doi.org/10.1093/ptj/77.12.1755

Christensen, D. L., Braun, K. V. N., Baio, J., Bilder, D., Charles, J., Constantino, J. N., \& Lee, L. C. (2019). Prevalence and Characteristics of Autism Spectrum Disorder Among Children Aged 8 Years - Early Autism and Developmental Disabilities Monitoring Network, 11 Sites, United States, 2012. MMWR Surveillance Summaries, 68(2), 1. https://doi.org/10.15585/mmwr.ss6802a1

Corder, G. W., \& Foreman, D.I. (2009). Nonparametric statistics for non-statisticians: A step-by-step approach. Hoboken, NJ: John Wiley \& Sons, Inc. https://doi.org/10.1002/9781118165881

deBruin, C., Deppeler, J., Moore, D., \& Diamond, N. (2013). Public school-based interventions for adolescents and young adults with an autism spectrum disorder: A meta-analysis. Review of Educational Research, 83(4), 521-550. https://doi.org/10.3102/0034654313498621

Groves, R. M., Fowler Jr, F. J., Couper, M. P., Lepkowski, J. M., Singer, E., \& Tourangeau, R. (2011). Survey methodology (Vol. 561). Hoboken, NJ: John Wiley \& Sons, Inc..

Kogan, M. D., Vladutiu, C. J., Schieve, L. A., Ghandour, R. M., Blumberg, S. J. Zablotsky, ... Lu, M. C. (2018). The prevalence of parent-reported autism spectrum disorder among US children. Pediatrics, 142(6), 1-13. https://doi.org/10.1542/peds.2017-4161

Lepage, P., \& Courey, S. (2014). Teaching children with high-level autism: Evidence from families. New York, NY: Routledge. https://doi.org/10.4324/9780203762356

McIntyre, N. S., Solari, E. J., Grimm, R. P., Lerro, L. E., Gonzales, J. E., \& Mundy, P. C. (2017). A comprehensive examination of reading heterogeneity in students with high functioning autism: Distinct reading profiles and their relation to autism symptom severity. Journal of Autism and Developmental Disorders, 47(4), 1086- 1101. https://doi.org/10.1007/s10803-017-3029-0

Mckeithan, G. K., \& Sabornie, E. J. (2019). Interventions for secondary students with high functioning autism in general education settings: A descriptive review. Exceptionality, 27(2), 81-100. https://doi.org/10.1080/09362835.2017.1359607

McKeithan, G. K., \& Sabornie, E. J. (2020). Social-behavioral interventions for secondary-level students with high-functioning autism in public school settings: A meta-analysis. Focus on Autism and Other Developmental Disabilities, 35(3), 165-175. https://doi.org/10.1177/1088357619890312

McKenney, E. L., Stachniak, C., Albright, J., Jewell, J. D., \& Dorencz, J. M. (2016). Defining success for students with autism spectrum disorder: Social academic behavior in secondary general education settings. Education and Training in Autism and Developmental Disabilities, 51(3), 318-327.

Precise, N., Finch, K., \& Macgregor, C. (2018). Professional development needs for general education teachers to educate children with autism spectrum disorders. The Advocate, 23(5), 6. https://doi.org/10.4148/2637-4552.1011

Quill, K. A., \& Stansberry-Brusnahan, L. L. (2017). Do-watch-listen-say: Social and communication intervention for autism spectrum disorder (2nd ed.). Baltimore, MD: Paul H. Brooks Publishing.

Riccomini, P. J., Morano, S., \& Hughes, C. A. (2017). Big ideas in special education: Specially designed instruction, high-leverage practices, explicit instruction, and intensive instruction. Teaching Exceptional Children, 50(1), 20-27. https://doi.org/10.1177/0040059917724412

Roberts, J., \& Simpson, K. (2016). A review of research into stakeholder perspectives on inclusion of students with autism in mainstream schools. International Journal of Inclusive Education, 20(10), 1084-1096. https://doi.org/10.1080/13603116.2016.1145267

Simpson, R. L., \& McGinnis-Smith (2019). Social skills success for students with Asperger syndrome and high-functioning autism. Thousand-Oaks, CA: Corwin.

Sirkin, R. M. (2006). Statistics for the social sciences. (3rd ed.). Thousand-Oaks, CA: Sage Publications, Inc. https://doi.org/10.4135/9781412985987

Steinbrenner, J. R., Hume, K., Odom, S. L., Morin, K. L., Nowell, S. W., Tomaszewski, B., Szendrey, S., ... Savage, M. 
N. (2020). Evidence-based practices for children, youth, and young adults with Autism. The University of North Carolina at Chapel Hill, Frank Porter Graham Child Development Institute, National Clearinghouse on Autism Evidence and Practice Review Team.

Stokes, M. A., Thomson, M., Macmillan, C. M., Pecora, L., Dymond, S. R., \& Donaldson, E. (2017). Principals' and teachers' reports of successful teaching strategies with children with high-functioning autism spectrum disorder. Canadian Journal of School Psychology, 32(3-4), 192-208. https://doi.org/10.1177/0829573516672969

Thomeer, M. L., McDonald, C. A., Rodgers, J. D., \& Lopata, C. (2019). High-functioning autism spectrum disorder: A framework for evidence-based practice. School Mental Health, 11(1), 29-39. https://doi.org/10.1007/s12310-017-9236-1

Travers, J. C., Krezmien, M. P., Mulcahy, C., \& Tincani, M. (2014). Racial disparity in administrative autism identification across the United States during 2000 and 2007. The Journal of Special Education, 48(3), 155-166. https://doi.org/10.1177/0022466912454014

Walker, B. A., Ficklin, A., Alexander, H., Gullett, L., Myers, L., \& Lewis, J. (2017). Effective strategies to influence performance of students with autism spectrum disorder within inclusive classrooms. American Journal of Occupational Therapy, 71(4_Supplement_1). https://doi.org/10.5014/ajot.2017.71S1-PO2091

Wei, X., Yu, J. W., Shattuck, P., \& Blackorby, J. (2017). High school math and science preparation and postsecondary STEM participation for students with an autism spectrum disorder. Focus on Autism and Other Developmental Disabilities, 32(2), 83-92. https://doi.org/10.1177/1088357615588489

Wittenburg, H. N., Cimera, R. E., \& Thoma, C. A. (2019). Comparing employment outcomes of young adults with autism: Does postsecondary educational experience matter? Journal of Postsecondary Education and Disability, 32(2), 159-172. https://doi.org/10.3233/JVR-201079

Zajic, M. C., McIntyre, N., Swain-Lerro, L., Novotny, S., Oswald, T., \& Mundy, P. (2018). Attention and written expression in school-age, high-functioning children with autism spectrum disorders. Autism, 22(3), $245-258$. https://doi.org/10.1177/1362361316675121

\section{Copyrights}

Copyright for this article is retained by the author(s), with first publication rights granted to the journal.

This is an open-access article distributed under the terms and conditions of the Creative Commons Attribution license which permits unrestricted use, distribution, and reproduction in any medium, provided the original work is properly cited. 